Для цитирования: Костин А.К., Рудницкий В.А., Сазонова О.В., Никитина В.Б., Епанчинцева Е.М., Иванова А.А., Гарганеева Н.П., Цыбульская Е.В., Перчаткина О.Э., Белокрылова М.Ф. Клинические и социальнопсихологические факторы, определяющие приверженность к терапии пациентов с соматоформными расстройствами. Сибирский вестник психиатрии и наркологии. 2020; 2 (107): 14-25. https://doi.org/10.26617/18103111-2020-2(107)-14-25

\title{
Клинические и социально-психологические факторы, определяющие приверженность к терапии пациентов с соматоформными расстройствами
}

\author{
${ }^{1}$ Костин А.К., ${ }^{1,2}$ Рудницкий В.А., ${ }^{1}$ Сазонова О.В., ${ }^{1}$ Никитина В.Б., \\ 1Епанчинцева Е.М., 1Иванова А.А., 2Гарганеева Н.П., 1Цыбульская Е.В., \\ 'Перчаткина О.Э., 1, 2Белокрылова М.Ф.
}

\author{
${ }^{1}$ Научно-исследовательский институт психического здоровья, Томский национальный исследовательский \\ медииинский центр Российской академии наук (НИИ психического здоровья Томский НИМЦ) \\ Россия, 634014, Томск, ул. Алеутская, 4 \\ ${ }^{2}$ Сибирский государственный медииинский университет \\ Россия, 634050, Томск, Московский тракт, 2
}

\section{PEЗЮME}

В настоящее время соматоформные расстройства, и особенно многообразная соматоформная симптоматика, широко распространенные в контингенте лиц трудоспособного возраста, зачастую длительное время остаются без надлежащей и адекватной диагностики и лечения, в связи с отсутствием своевременной терапии имеют склонность к хроническому течению. Несмотря на значительное число публикаций в научной литературе, исследователями уделяется недостаточно внимания клиническим проявлениям, социальным и микросоциальным факторам в патогенезе соматоформных расстройств. Цель исследования: изучить взаимосвязи клинических и социально-психологических факторов, определяющих комплаентность и прогноз при лечении пациентов с соматоформными расстройствами. Материалы и методы: на базе отделения пограничных состояний НИИ психического здоровья обследовано 150 больных (53 мужчины и 97 женщин, средний возраст которых составил 40,4 4,5 года) с установленным диагнозом соматоформного расстройства в соответствии с диагностическими критериями МКБ-10. Пациенты подразделялись по возрастному параметру, клинической картине течения заболевания и клинико-патогенетическому варианту. В работе использовались клиникопсихопатологический, клинико-динамический, клинико-катамнестический, психологический (шкала Спилбергера-Ханина, тест ММИЛ - Методика многостороннего исследования личности, тест Актуальное психическое состояние, Торонтская шкала алекситимии и тест Е. Неin (1988) для определения копинг-механизмов в модификации И.Я. Стояновой), статистический методы. Результаты: анализ психотравмирующих ситуаций выявил, что наибольшее значение имели внутрисемейные психотравмы (63,3\%). Аномальные формы воспитания имели место у 92,7\% пациентов. Особенности внутренних представлений о болезни пациентов с соматоформными расстройствами в зависимости от преобладания когнитивных, поведенческих и аффективных паттернов реагирования определяли формирование и состояние терапевтического альянса и приверженность к терапии. Рассмотрены основные клинико-патогенетические варианты, социальные и микросоциальные факторы, влияющие на процесс психофармакотерапии и комплексной психосоциальной реабилитации пациентов. Заключение: психологические, индивидуально-личностные особенности пациентов, стили их семейного воспитания и функционирования вносят существенный вклад в развитие психической дезадаптации, оказывают существенное влияние на формирование и течение соматоформных расстройств, препятствуют установлению полноценного комплаенса на всех этапах терапии и реабилитации пациентов, определяют прогноз и показания для длительного психотерапевтического сопровождения пациентов после выписки из психиатрического стационара.

Ключевые слова: непсихотические психические расстройства, соматоформные расстройства, дезадаптация, особенности внутренних представлений о болезни, клинические и социально-психологические факторы, точность выполнения терапевтических назначений, персонализированная терапия, психотерапия, психокоррекция, психофармакотерапия. 


\section{ВВЕДЕНИЕ}

В настоящее время во всём мире отмечается отчетливая тенденция к увеличению распространенности невротических, связанных со стрессом, тревожных расстройств. Согласно данным Американской психиатрической ассоциации (AРА, 2004), распространенность соматоформных расстройств составляет около $1 \%$ населения, женщины болеют значительно чаще мужчин, заболевание более распространено среди бедных и малообразованных слоев населения. ВОЗ приводит данные, что не менее 25\% пациентов общесоматических клиник обнаруживают соматоформные расстройства. К сожалению, в отечественной и зарубежной литературе практически отсутствует современная информация по эпидемиологии соматоформных расстройств. По данным зарубежных авторов, результаты в этой области изучения отличаются статистической гетерогенностью при среднем уровне проведения научных исследований $[1,2]$. Отмечается тенденция к выделению группы симптомов, не объяснимых с общемедицинской позиции, что трактуется как донозологическая категория с размытыми критериями диагностики и в отечественной традиции может быть соотнесено с общим психосоматическим синдромом. Высокая распространенность соматоформных расстройств, возможно, связана с общей тенденцией к соматизации и редукции психопатологических проявлений при всех психических заболеваниях вследствие патоморфоза на клиническом уровне. Изучение общей популяции показало, что у 77,9\% лиц с соматоформными симптомами выявляется дополнительная симптоматика. Проявления соматизации, диссоциации, депрессии и тревоги, согласно современным данным, обнаруживают высокий уровень коморбидности [3]. Роль зависимостей и аддикций [4], психологических особенностей, психогенных и семейных факторов в генезе психических, психосоматических, соматоформных расстройств подчеркивалась многими исследователями $[5,6,7,8,9]$. В то же время недостаточно внимания уделялось клиническим проявлениям, макро- и микросоциальным и факторам в патогенезе данных расстройств. В нашем исследовании акцент сделан именно на них, поскольку соматоформные расстройства возникают, протекают и видоизменяются в тесной взаимосвязи с личностью пациента, на формирование и функционирование которой значимое влияние оказывают семья и микроокружение больного.

\section{ЦЕЛЬ ИССЛЕДОВАНИЯ}

Изучить взаимосвязи клинических и социально-психологических факторов, определяющих комплаентность и прогноз при лечении соматоформных расстройств.

\section{МАТЕРИАЛЫ И МЕТОДЫ}

На базе отделения пограничных состояний обследовано 150 больных (53 мужчины и 97 женщин, средний возраст - 40,4 44,5 года) с установленным диагнозом соматоформного расстройства по диагностическим критериям МКБ10. Пациенты подразделялись по трем параметрам: возрасту, клинической картине течения заболевания, клинико-патогенетическому варианту. В рамках исследования использовались клинико-психопатологический (оценка симптомов, синдромов и состояний больных в условиях воздействия семейных психогенных факторов), клинико-динамический (изучение особенностей формирования и динамики психосоматических расстройств личности при воздействии семейных психогений), клинико-катамнестический (ретардированная оценка динамики клинических характеристик заболевания), психологический (шкала Спилбергера-Ханина, тест ММИЛ - Методика многостороннего исследования личности, тест АПС - Актуальное психическое состояние, Торонтская шкала алекситимии, тест E. Hein (1988) для определения копингмеханизмов в модификации И.Я. Стояновой), статистический методы. Пациенты при включении в исследование заполняли бланк информированного добровольного согласия. Определены критерии включения пациентов в исследовательскую выборку (наличие соматоформных расстройств) и критерии исключения (наличие эндогенных, аддиктивных расстройств, тяжелых соматических заболеваний в стадии обострения).

\section{РЕЗУЛЬТАТЫ И ОБСУЖДЕНИЕ}

Анализ психотравмирующих ситуаций выявил наиболее высокую значимость психотравмирующих воздействий внутри семьи (63,3\%). В каждой возрастной группе структура психогений менялась, но оставалась тесно связанной с семейными проблемами. Так, в возрастной группе до 20 лет значимыми были потери и неблагоприятные отношения в ядерной семье, соматогенные вредности. В возрастной группе 20-30 лет деструктивными факторами являлись беременность и роды, миграция, проблемы в собственной семье: материальное неблагополучие, психологический дискомфорт, супружеские измены. В возрастной группе 30-40 лет психотравмирующими были следующие ситуации: развод, конфликты на работе. 
Аномальные формы воспитания имели место у большинства $(92,7 \%)$ пациентов. Среди неправильных типов воспитания преобладали гипоопека и воспитание по типу «кумира семьи» (достоверно чаще встречавшееся у лиц с истерическим расстройством личности). Деструктивным воздействием обладал и комбинированный тип неправильного воспитания. Пациенты в $62 \%$ случаев воспитывались в полной семье, в остальных случаях воспитанием занимался один из родителей или родственники. Гармоничные отношения в семье отметили более половины пациентов $(58,0 \%)$, в остальных семьях имели место частные скандалы или ровные, холодные, безразличные отношения, что согласуется с данными китайских исследователей об отрицательной связи возникновения соматоформной симптоматики с семейной сплоченностью и адаптивностью [10].

При рассмотрении системы факторов, оказывающих влияние на индивида, нами были выделены 2 основные группы внешних воздействий: факторы дефицита с отсутствием удовлетворения потребностей пациента и внешние психогенные воздействия. Собственно психогении, в свою очередь, подразделялись по параметрам интенсивности, специфичности, продолжительности, повторяемости и осознанности. Интенсивные, катастрофические психогении, такие, например, как утрата близких родственников, обычно на хорошем уровне осознавались, тем более их воздействие было психологически понятно и объяснимо. Напротив, длительно протекающие психогении слабой степени интенсивности становились привычными и редко понимались пациентами, превращаясь шаблонно-привычную картину семейной жизни, что еще более усугублялось при наличии алекситимичемкого радикала личности. Необходимо подчеркнуть специфичность семейных психогений, уязвимость к ним пациентов с соматоформными расстройствами, что нередко использовалось ближайшим окружением как средство манипулирования пациентом, удержания в сфере своего влияния. Постепенно, но неуклонно происходило накопление психогений, нарастание внутреннего напряжения, астении и истощения. Невозможность психического отреагирования, слабая дифференцированность психических и соматических феноменов, недопустииость проявления отрицательных эмоций - всё это приводило к манифестации и становлению соматоформной симптоматики.
Отмечались неосознаваемые пациентами несоответствия между декларированной потребностью в близких и доверительных отношениях и контактах, к которым пациент обычно был не способен, с отгороженностью от окружающих и недоброжелательным к ним отношением. Требования и призывы о помощи сочетались с невыполнением условий и правил лечения, несогласием с требованиями гарантий их эффективности, уклонением от лечебных предписаний, а также с агрессивной, пассивнооборонительной или пассивно-агрессивной позицией на психотерапевтических группах, с неоднократными пропусками сеансов психотерапии, предпочтением физических, телесноориентированных методов лечения перед психологическими техниками.

Обращаясь за помощью к медицинским работникам, пациент проецировал на них образы родительских фигур и пытался выстроить систему взаимоотношений с терапевтом, подобную сложившейся в его в семье. У врачей соматического профиля, особенно работающих в первичном звене, в условиях ограниченности времени приема не было возможности полноценно удовлетворить нереализованные в потребности пациента, который затруднялся с определением собственных психологических границ. Предъявляемые им многочисленные, полиморфные жалобы, с размытой их динамикой или их быстрым возвращением вели к многочисленным повторным обращениям за медицинской помощью, обесцениванию проводимой терапии как самим врачом, так и пациентом, что, в конечном счете, приводило к дистанцированию врача и пациента, нарушению комплаентности, девальвации усилий врача и обращению к другому специалисту.

$\mathrm{y}$ пациентов с соматоформными расстройствами желудочно-кишечного тракта, особенно с тяжелым течением данных расстройств, отсутствовало разграничение трех сфер: психической, соматической и социальной, были размыты границы между значимыми близкими и самим пациентом, который был не готов дистанцироваться и отпускать что-либо или коголибо. Характерной была боязнь новизны со страхом потери уже ранее известного, незнакомые сценарии всегда казались угрожающеопасными. Наличие паранойяльных черт способствовало формированию внешнеобвиняющей позиции и провоцированию окружающих, в том числе медицинских работников, на проявление негативного отношения к ним [11]. 
Рассмотрение копинг-механизмов с помощью теста Е. Hein (1988) выявило следующие параллели. Была обнаружена недостаточная развитость сферы контактов - пациенты чаще выбирали отвлечение и активное избегание, а в $46,0 \%$ случаев отрицали сотрудничество как таковое. Озлобленность, гнев и протест не выражаются ими открыто, соответственно подавление эмоций выходит на первое место, отвергаются агрессивность и протест. Т.е. недостаточная психическая гибкость отражается в сфеpax эмоциональной, когнитивной и общения. Оценив влияние отдельных областей деятельности пациентов, отмечено, что неадаптивные стратегии чаще встречались в когнитивной сфере (диссимуляция - 56,7\%, игнорирование - 43,3\%). Однако в сфере эмоций второе место пришлось на наиболее распространенный механизм, ассоциировавшийся с соматоформными расстройствами гастроинтестинальной системы (подавление эмоций - 86,0\%).

Среди пациентов с соматоформными расстройствами нами выделены 3 клиникопатогенетических варианта: 1) конституциональный, при котором пациенты изначально предъявляли соматоформную симптоматику в ответ на воздействие психогений, у них всегда отсутствовало разграничение психического и телесного, характерным был феномен семейной алекситимии и семейного накопления; 2) патохарактерологический, характеризовавшийся изменениями личности в когнитивной, поведенческой и эмоциональной сферах; 3) критический, возникавший остро с появлением соматоформной симптоматики как признака дезадаптации, декомпенсации. Конституциональный вариант чаще встречался среди лиц до 20 лет, так же как и критический вариант - до 20 и в 20-30 лет. У пациентов от 30 до 40 лет и старше преобладал патохарактерологический вариант. Рассматривая клиникопатогенетические варианты в динамическом континууме, следует отметить, что при неблагоприятном прогнозе, во многом обусловленном факторами семейного окружения, критический вариант может переходить в патохарактерологический и способствовать в последующих поколениях появлению конституциального.

В клинической картине преобладала соматоформная симптоматика со стороны сердечнососудистой системы, второе место занимала симптоматика со стороны желудочнокишечного тракта и на третьем месте - со стороны дыхательной системы. Соматоформные симптомы со стороны других систем органов встречались значительно реже. Наиболее часто пациентам устанавливался диагноз недифференцированного соматоформного расстройства, с меньшей частотой - соматизированного расстройства и соматоформной вегетативной дисфункции сердечно-сосудистой системы и желудочно-кишечного тракта. Диагноз соматоформной вегетативной дисфункции встречался в единичных случаях. При установлении диагноза соматизированого расстройства отмечалась тенденция к росту частоты встречаемости патохарактерологического варианта.

В психологическом «портрете» пациентов с соматоформными расстройствами в ходе обследования обнаруживается высокий удельный вес значимости наиболее важных патохарактерологических качеств: ригидность $(76,0 \%)$, тревожность $(75,3 \%)$, мнительность, $(68,7 \%)$, ипохондрический эгоцентризм $(67,3 \%)$, астеничность $(63,3 \%)$, раздражительность и дистимичность $(61,3 \%)$, сенситивность $(52,7 \%)$, демонстративность и жажда внимания $(51,3 \%)$, алекситимичность $(45,3 \%)$.

Отмечалось большое число сочетаний патохарактерологических черт, которые совместно создавали «фасад» пациента, препятствующий формированию комплаентных отношений с врачом и, соответственно, затрудняли диагностику, терапию и реабилитацию.

Отмечались недостаточность терапевтического альянса и искаженное представление о болезни, лечении и собственной роли в процессе терапии $(72,7 \%$ больных фактически не считали лечение своей задачей, а полностью делегировали её врачу, испытывали проблемы со своей идентификацией, отказываясь признать себя пациентами психиатрического профиля. По крайней мере, существовал несоизмеримо большой разрыв между формальным признанием себя пациентом и осознанной готовностью разделить с врачом ответственность за реализацию процесса диагностики и лечения. Частично это было связано с регрессией пациентов в ходе лечения, в какой-то мере - с изначальными когнитивными искажениями. Данный вывод косвенно подтвержден результатами экспериментально-психологического обследования по методике ТОБОЛ - у пациентов выявлены ипохондрический, тревожно-мнительный, смешанный типы реагирования на заболевание. В структуре личности, определяемой по методике, преобладали эмотивные, истероидные, застревающие, тревожно-мнительные черты. 
Дисгармоничные семейные отношения находили отражение в проективных рисуночных тестах, в частности в рисунках «Я и моя семья», «Я и мой супруг», «Я и моя мать». Определялись нарушенные семейные границы, инфантильные, зависимые установки в поведении, нарушение полоролевой идентификации, что отражалось в размерах и расположении фигур на рисунках, детализации изображений. У пациентов с ведущей симптоматикой со стороны сердечно-сосудистой системы преобладали напряженность, ригидность, стремление к сверхконтролю, что зачастую сочеталось с анозогнозией, чаще у мужчин, либо гипонозогнозией с отказом от длительного приема психотропных препаратов. Пациенты с соматоформной симптоматикой со стороны желудочнокишечного тракта были более эмотивны, зависимы от окружения, тревожны, мнительны, фиксированы на соматической симптоматике.

Проективные методики демонстрировали несовпадение декларируемых и реальных ролей, играемых пациентом в течение жизни. Пациенты с соматоформной симптоматикой со стороны желудочно-кишечного тракта потенцировали себя как взрослых, независимых, ответственных, При этом в рисуночных тестах их фигуры были менее детализированы, меньшего размера, расположены ниже и вблизи от значимых родственников и лиц своего окружения. Лица с симптоматикой со стороны сердечнососудистой системы зачастую были склонны к переоценке собственной значимости, маскулинности. Проективные рисунки позволяли не только диагностировать те либо иные нарушения, но и определять перспективные задачи и методы терапии, отслеживать динамику взаимоотношений и состояния пациента.

Одним из распространенных психологических качеств пациентов с соматоформными расстройствами являлась алекситимичность, выраженность которой исследовалась с помощью Торонтской шкалы алекситимии (ТАC). Среди обследованных пациентов алекситимией не страдали $13,3 \% ; 41,3 \%$ относились к пограничной группе; у 45,3\% была обнаружена собственно алекситимия. Балл по ТАС в среднем составил $78 \pm 3$, что указывало на выраженную степень алекситимии. Высокий балл по ТАС был характерен для лиц с конституциональным клинико-патогенетическим вариантом, массивной психовегетативной симптоматикой со стороны различных органов и систем, с диагнозом соматизированного расстройства.
При патохарактерологичесском варианте балл по ТАС был ниже и чаще встречались пациенты с пограничной алекситимией. Значение данного фактора сложно переоценить, так как он отражает особенности формирования личности пациента в нуклеарной семье и является предиктором качества его функционирования в различных сферах, при создании собственной семьи и формирования болезненного состояния как способа патологической адаптации.

$\mathrm{У}$ значительного числа пациентов в момент актуального поступления был выявлен высокий уровень ситуативной тревожности. Так, по методике АПС почти у всех пациентов были снижены показатели по шкалам активности и работоспособности и повышены показатели по шкалам тревожности и напряженности.

Более чем у половины $(56,7 \%)$ пациентов с соматоформными расстройствами имел место феномен возрастной регрессии.

В литературе феномен возрастной регрессии описывается в связи с гипнотическими феноменами и техниками гипнотерапии. Возрастная регрессия (англ. age regression) - психофизиологическое состояние, вызываемое с помощью гипнотического внушения у взрослых здоровых людей, в котором у них возникают воспоминания и формы поведения, свойственные ранним периодам детства. По другому определению (Эриксон М., Росси Э., 1995) - это известная способность переживать в гипнозе прошедшие события в ответ на просьбу или спонтанно [12].

Однако мы усматриваем возможность его более широкого использования в клинической практике непсихотических психических расстройств как спонтанного либо спровоцированного возвращения пациентов к образцам эмоционального реагирования, свойственного для них в детстве. Ф. Александер приводит такое описание: «Вместо противостояния опасности их первый импульс - обратиться за помощью, т.е. так, как они поступали, будучи беспомощными детьми. Такой уход от действия к состоянию, свойственному организму во время релаксации, может быть назван «вегетативным уходом» [13].

Феномен возрастной регрессии проявлялся у большинства пациентов в процессе терапии, отличались лишь степень выраженности, глубина психологической регрессии и период пребывания в этом состоянии. Его возникновение обусловлено как самим болезненным состоянием с дефицитом личностных и средовых ресурсов с бессознательной попыткой их восполне- 
ния посредством демонстрации инфантильного поведения, так и заниманием значимыми близкими людьми позиции родителя, по терминологии Э. Берна. Это было обнаружено у пациентов еще при обращении в стационар, ряд из них обращались либо приходили на консультацию в сопровождении значимого близкого. На начальном этапе терапии отмечалось усиление возрастной регрессии, особенно характерное на фоне назначения седативных психотропных препаратов.

Возрастная регрессия являлась распространенным феноменом среди пациентов с непсихотическими психическими расстройствами, однако у пациентов с соматоформными расстройствами встречалась в 1,5 раза чаще $(56,7 \%$ против 38,0\% при расстройствах адаптации). Представления о возрастной регрессии соотносились с предъявляемыми пациентом множественными эмоционально окрашенными жалобами и его психологическими особенностями.

У пациентов преобладало эмоциональное реагирование с фиксацией на своем состоянии «здесь и сейчас» и предъявлением непосредственных реакций со склонностью к манипуляции с целью получения внимания и заботы. Когнитивные процессы реципрокно подавлялись, что соотносилось со степенью психологической регрессии и препятствовало осознанию пациентом своего состояния, формированию адекватных внутренних представлений о болезни, установлению рационального терапевтического альянса и проведению рациональной психотерапии, что характерно для кризисного этапа пребывания в стационаре, по терминологии В.Я. Семке [5]. Поэтому на данном этапе особо важным являлось принятие эмоций пациента, подтверждение их значимости, переключение его внимания на позитивно окрашенные события [14]. В процессе разъяснения симптоматики психических расстройств играла роль не только информационная составляющая, но и стиль и манера изложения материала, вербальные и невербальные признаки уверенности врача, его отношение к состоянию пациента.

Важным для формирования клинической картины являлось получение пациентом вторичной выгоды от своего болезненного состояния. Исходя из концепции душевных кризисов, разработанной В.Я. Семке [5] и продолжаемой нами в отношении пациентов с сочетанным воздействием экологических и психосоматических факторов, можно говорить о формировании у данных пациентов как экологического, так и психосоматического кризиса. Сформировавшееся и постоянно нарастающее социальномедицинское неблагополучие, обусловленное сложной сочетанностью психической и соматической патологии, явилось основой массивного социального стресса, накладывающегося на экологический стресс.

В клинической практике есть негативные представления о рентных установках, их всячески стараются избегать или игнорировать. На самом деле, рентные установки встречаются в повседневной жизни часто и представляют собой один из мотивов человека, подвигая его к поиску внимания и заботы. Отсутствие рентных установок приводило к тому, что пациент не обращался за помощью, пытаясь справиться со всем сам, «брал себя в руки» по рекомендации родных и знакомых, что чаще всего только усугубляло состояние - в данном случае возрастная регрессия позволяла без ущерба для самооценки требовать помощь от окружающих. При этом отсутствовали какие-либо представления о мере и границах личности, при попытке их установления пациент занимал позицию обиженного ребенка. Обилие негативных эмоций снижало у него понимание своего состояния, ощущения становились недифференцированными. Данное состояние сопровождалось проекцией негативного образа взрослых на врача, поскольку данная проекция являлась более безопасной, чем адресация подобных чувств к «реальным виновникам» и членам семьи, которые вскоре присоединялись к обвинениям пациента в сторону врача.

Для пациентов с устойчивым соматоформным болевым расстройством было характерно формирование созависимых, симбиотических отношений со значимыми людьми. Это можно рассматривать как вариант ранней травмы, когда родители воспринимали ребенка как часть себя либо как внешний мешающий объект, в силу чего эмоции и потребности ребенка игнорировались, любое их проявление жестко пресекалось. Проявление эмоций, интересов и потребностей становилось опасным, так как родительские желания реализовывались за счет ребенка. Поэтому единственной разрешенной стратегией становилось нарастание алекситимии, формирование преставлений о неприемлемости, разрушительности собственных эмоций и предъявление соматической симптоматики как способа адаптации к патологической ситуации. 
В данном случае можно говорить о «семейной алекситимии» и передаче паттернов психосоматического реагирования по наследству, когда алекситимичные родители не могут научить ребенка проявлять эмоции и взаимодействовать с ними, а предъявление соматической симптоматики становится частью семейного и социального функционирования. У пациентов отмечался феномен семейного накопления, когда несколько членов семьи страдали одним и тем же расстройством. В частности он отмечался у пациентов с соматоформной вегетативной дисфункцией нижней части ЖКТ синдром раздраженного кишечника, по терминологии гастроэнтерологов, что согласуется с данными отечественных и зарубежных авторов $[7,8,9]$. По их представлению, это социально детерминированное обучение гастроинтестинальным симптомам под давлением внешних обстоятельств, передача патологических паттернов поведения от родителей к детям. Высока значимость семейного окружения при формировании комплаентных отношений с пациентом, особенно на этапе поддерживающей терапии, когда родственники пациента, зачастую получающие вторичную выгоду от его болезненного состояния, инициируют прекращение лечения, конкурируя с врачом за «власть» над пациентом. Соответственно для пациентов с соматоформными расстройствами был характерен высокий уровень семейной дезадаптации.

Восприятие родственниками состояния пациента чаще всего характеризовалось преувеличением тяжести с усилением контроля, окружением заботой, усилением зависимости от себя с разрушением любых других социальных взаимодействий и альянсов, в том числе и терапевтического, к чему были склонны тревожные контролирующие личности. Второй вариант, представленный обесцениванием состояния пациента и описываемый как его «придумка», позволял избежать необходимости понимания объективных причин его состояния, что особо значимо для «тонкой материи» психических расстройств, любых проявлений ответственности за него и, следовательно, какихлибо действий. Встречался и третий вариант, когда декларировалась необходимость обращения за помощью, обещалась поддержка и подчеркивалась активная роль самого пациента в лечении заболевания. Однако при этом амбивалентно его внимание акцентировалось на вредности назначаемого лечения, недопустимости длительного курса терапии и приема больших доз препаратов. Родственники продолжали жить прежней жизнью, собственными интересами, а чувства и переживания пациента отрицались. У пациента на этом фоне нарастала дистимическая, соматоформная и сенестопатическая симптоматика, усиливалось непонимание актуальной ситуации, что вело к саботажу проводимой терапии, ухудшению самочувствия и закономерному обвинению медицинских работников в оказании неквалифицированной помощи.

При патохарактерологическом варианте соматоформного расстройства пациент дистанцировался от своих переживаний и акцентировался на значимости страдания. Пациент учился «ценить» свои страдания, болезнь начинала занимать все более значимое место в его жизни с развитием вариантов небредовой ипохондрии и расстройства личности $[15,16]$. Учет подобных феноменов использовался нами в построении терапевтической тактики и стратегии ведения пациентов с соматоформными расстройствами. Основным принципом психотерапевтического лечения являлась его направленность на личность больного, а не на больной орган или систему. Психотерапия была ориентирована на устранение недостатка информации о соматическом и психическом состоянии, нейтрализацию ятрогенных воздействий, имевших место на предшествующих этапах лечения (до обращения к психиатру), исправление когнитивных ошибок, выработку новых поведенческих паттернов, интеграцию аффектов и повышение толерантности к фрустрации, коррекцию семейных взаимоотношений [17].

Пациенты с соматоформными нарушениями не были склонны к прерыванию процесса лечения, но вносили в него изменения без согласования с рекомендациями врача, что сопровождалось самостоятельным снижением доз препаратов и возвращением прежней симптоматики или, наоборот, повышением доз, полипрагмазией, ростом побочных эффектов терапии либо противоречивыми неадекватным назначением несогласованной терапии различных заболеваний разными врачами. Психотерапевтический комплекс включал различные модификации аутогенной тренировки, позволяющей снизить тревожность пациентов, обучить их самостоятельно стабилизировать вегетативные реакции. В ряде случаев ей предшествовало ознакомление пациента с ощущениями, возникающими в теле, научение их вербализации (преодоление алекситимичности). 
В дальнейшем проводилась рациональная, когнитивная психотерапия (работа с личностными и средовыми ресурсами для повышения уровня адаптации и самоактуализации пациента в социуме, семейной и производственной сферах, анализ и коррекция копинг-стратегий). Эффективным являлось обучение элементам бихевиоральной терапии (анализ типичных стрессовых ситуаций, составление планов деятельности с использованием правил составления аффирмации и нарабатывание навыков поведения в них, обучение методикам отреагирования агрессивных побуждений, эмоций) [18], элементам нейролингвистического программирования (фиксация соматических состояний, утилизация трансов). Также использовались групповая и семейная психотерапия. Групповая психотерапия давала пациентам возможность избавиться от ощущения уникальности собственных проблем, что было важным шагом на пути к преодолению социальной изоляции. Групповая сплоченность позволяла им ощутить поддержку других людей, способствовала развитию базовых навыков общения. Семейная психотерапия оптимизировала взаимоотношения в семье пациента, устраняя один из важнейших патогенетических факторов возникновения и развития психосоматической патологии, устраняла связанные с этим напряжение, тревогу, беспокойство, что позволяло предотвратить повторные обострения. Принятие и эмоциональная поддержка пациента, индивидуализированность эмоциональных реакций, их свободное и искреннее проявление служили основой для установления более глубоких неформальных межличностных контактов.

В тематике психотерапевтических групп при использовании ассоциативного подхода доминировали проблемы взаимоотношения с родителями и детьми, с выраженной эмоциональной разрядкой, возрастной регрессией, обращением в прошлое, обвинениями в отношении членов семьи и медицинских работников. Первоначально врачи обычно идеализировались и воспринимались с чрезмерным энтузиазмом, пациент обращался к ним за «спасением», «исцелением» с подчеркиванием того, что только данный врач способен им помочь. Однако в ходе терапии при средней либо медленной динамике состояния быстро формировались обесценивание, враждебность по отношению к врачу со стороны пациента с разрывом терапевтических отношений.
Для пациентов с соматоформными расстройствами характерным являлся поиск идеального родителя и оптимального врачапартнера с сопоставлением существующего воображаемого образа и реальных людей, всегда проигрывавших этому представлению, принципиальной их недостижимостью, бесперспективностью поисков и последующим обесцениванием. В большей мере это характерно для пациентов с преобладанием истерических черт. При доминировании тревожных черт было характерно формирование зависимых, симбиотических отношений, где страх утраты значимой фигуры способствовал сохранению формальных, дистантных отношений, зачастую напоминающих таковые в семье пациента.

Проекция образов родителей на значимых близких, не сформировавших полноценного детско-родительского взаимодействия, согласно терминологии Э. Берна, способствовала появлению ощущения отверженности, ненужности, тревоги, страха, отсутствию уверенности в завтрашнем дне. Повышались уровни личностной и ситуационной тревоги, агрессии, которые не выражались открыто из-за страха утраты даже таких болезненных взаимоотношений. Формировался контроль раздражения с самообвинением и формированием депрессивных переживаний, вытеснением эмоциональных переживаний в соматическую сферу, которая позволяла объяснить себе и окружающим нарушение адаптации во всех сферах функционирования пациента.

В фармакотерапии по клиническим показаниям использовались антидепрессанты, нейролептики, транквилизаторы и средства, улучшающие метаболизм ЦНС. Психофармакологический и фармакологический комплексы включали применение соматотропной терапии, назначение антидепрессантов (флуоксетин, пароксетин, эсциталопрам, флувоксамин, миансерин, миртазапин), вегетостабилизаторов (беллатаминал), нейролептиков (сульпирид, тералиджен, хлорпротиксен, кветиапин), транквилизаторов бензодиазепинового ряда (сибазон, алпразолам, феназепам), ноотропов (пирацетам, пикамилон), полипептидных препаратов (кортексин). Подбор комплексного алгоритма лекарственной терапии производился с учетом принципа персонализированности и на основании максимальной эффективности при минимуме побочных эффектов со стороны гастроинтестинального тракта. 
Психопрофилактический этап начинался перед выпиской при констатации значительного улучшения состояния. С пациентом обсуждались вопросы семейной коррекции, социальной адаптации, формировалась система переключения эмоций и акцентирования внимания на минимальных симптомах проявления декомпенсации, возможности медикаментозной и психологической коррекции. При формировании психопрофилактических стратегий акцентировали внимание на личной ответственности пациента за выздоровление, необходимости включения в психопрофилактическую стратегию регулярного медикаментозного лечения. Информационно-образовательная программа для пациентов включала формирование представления о строении и функционировании нервной системы, возникновении психических расстройств, принципах поддерживающей терапии, сопутствующих заболеваниях, стрессе, здоровом образе жизни, психогигиене. Особое значение в виду личностных особенностей пациентов данной группы приобретают мероприятия, оптимизирующие рентные установки, искаженные внутренние представления пациента о болезни и процессе лечения, поддерживающей психофармако- и психотерапии.

\section{ЗАКЛЮЧЕНИЕ}

Психологические, личностные особенности пациентов, особенности их семейного воспитания и функционирования в окружающей среде вносят весомый вклад в психическую дезадаптацию, оказывают существенное влияние на формирование и течение соматоформных расстройств, препятствуют формированию полноценного комплаенса на всех этапах терапии и реабилитации пациентов, определяют прогноз и показания для их длительного психотерапевтического сопровождения.

У большинства пациентов был сформирован социальный стереотип поведения, когда наличие соматических проявлений нездоровья воспринималось как единственное одобряемое условие обращения за помощью к окружающим и получения от них внимания, заменяющего проявление любви и заботы. Наличие соматических симптомов оправдывало снижение требований к себе в различных сферах функционирования пациента и повышение социальных претензий. Алекситимия и соматизация аффективных проявлений создавали условия для дальнейшей фиксации на телесной сфере и объясняли предпочтение соматически ориентированных медицинских интервенций.
Поэтому не вызывает сомнений необходимость разработки реабилитационных и превентивных мероприятий, направленных на коррекцию внутренних представлений о болезни, формирование терапевтического альянса, коррекцию патологических семейных отношений и предотвращение «передачи по наследству» паттернов психосоматического реагирования.

\section{КОНФЛИКТ ИНТЕРЕСОВ}

Авторы заявляют об отсутствии явных и потенциальных конфликтов интересов в связи с публикацией данной статьи.

\section{ИСТОЧНИК ФИНАНСИРОВАНИЯ}

Исследование выполнено в рамках комплексной темы НИР «Комплексное исследование клинико-психопатологических закономерностей и патобиологических механизмов формирования и прогредиентности социально значимых психических и поведенческих расстройств с разработкой инновационных методов ранней диагностики, персонализированных стратегий терапии и профилактики» (регистрационный номер AAAAA19-119020690013-2).

\section{СООТВЕТСТВИЕ ПРИНЦИПАМ ЭТИКИ}

Исследование проведено с соблюдением норм современной биомедицинской этики и этических стандартов, разработанных в соответствии с Хельсинской декларацией ВМА (протокол заседания этического комитета НИИ психического здоровья Томского НИМЦ № 53/1.2012 от 1 октября 2012 г.).

\section{ЛИТЕРАTУРA/REFERENCES}

1. Haller H., Cramer H., Lauche R., Dobos G. Somatoform disorders and medically unexplained symptoms in primary care - a systematic review and metaanalysis of prevalence. Dtsch Arztebl Int. 2015 Apr 17; 112(16):279-87. DOI: 10.3238/arztebl.2015.0279

2. Claassen-van Dessel N., Van der Wouden J., Dekker J., Van der Horst H. Clinical value of DSM IV and DSM 5 criteria for diagnosing the most prevalent somatoform disorders in patients with medically unexplained physical symptoms (MUPS). J Psychosom Res. $2016 \quad$ Mar;82:4-10. DOI: 10.1016/j.jpsychores.2016.01.004

3. Собенников В.С. Соматизация и соматоформные расстройства. Иркутск, 2014: 304. Sobennikov V.S. Somatization and somatoform disorders. Irkutsk, 2014: 304 (in Russian).

4. Бохан Н.А., Мандель А.И., Артемьев И.А., Ветлугина Т.П., Солонский А.В., Прокопьева В.Д., Иванова С.А., Невидимова Т.И. Эпидемиология, патобиологические закономерности и профилактика психических и поведенческих расстройств в результате злоупотребления психоактивными веществами (региональный аспект). Сибирский вестник психиатрии и наркологии. 2006;3(42): 25-32. Bokhan N.A., Mandel A.I., Artemyev I.A., Vetlugina T.P., Solonsky A.V., Prokopyeva V.D., Ivanova S.A., Nevidimova T.I. Epidemiology, pathobiological regulatrities 
of prevention of mental and behavioral disorders as a result of substance abuse (regional aspect). Siberian Herald of Psychiatry and Addiction Psychiatry. 2006;3(42): 25-32 (in Russian).

5. Семке В.Я. Истерические состояния. М.: Медицина, 1988: 224. Semke V.Ya. Hysterical states. Moscow: Publishing House Medicine, 1988: 224 (in Russian).

6. Белокрылова М.Ф., Семке В.Я. Привязанность, зависимость, симбиоз. Томск: МГП «РАСКО», 2001: 104. Belokrylova M.F., Semke V.Ya. Attachment, addiction, symbiosis. Tomsk: Publishing House "RASKO", 2001: 104 (in Russian).

7. Levy R.L., Jones K.R., Whitehead W.E., Feld S., Talley N.J., Corey L.A. Irritable bowel syndrome in twins: heredity and social learning both contribute to etiology. Gastroenterology. 2001 Oct; 121(4):799804. DOI:10.1053/gast.2001.27995

8. Pace F., Zuin G., Di Giacomo S., Molteni P., Casini V., Fontana M., Porro G. Family history of irritable bowel syndrome is the major determinant of persistent abdominal complaints in young adults with a history of pediatric recurrent abdominal pain. World Journal of Gastroenterology. 2006 July; 12(24):3874-7. DOI: 10.3748/wjg.v12.i24.3874

9. Аксенов М.М., Семке В.Я., Белокрылова М.Ф., Куприянова И.Е., Епанчинцева Е.М., Ветлугина Т.П., Иванова С.А., Гуткевич Е.В., Кусков М.В., Стоянова И.Я., Лебедева В.Ф., Рудницкий В.А., Перчаткина О.Э., Никитина В.Б., Васильева Н.А., Агарков А.А. Типология, конституциональнобиологические и клинико-динамические характеристики кризисных состояний при пограничных нервно-психических расстройствах. Сибирский вестник психиатрии и наркологии. 2009; 5(56): 915. Aksenov M.M., Semke V.Ya., Belokrylova M.F., Kupriyanova I.E., Epanchintseva E.M., Vetlugina T.P., Ivanova S.A., Gutkevich E.V., Kuskov M.V., Stoyanova I.Ya., Lebedeva V.F., Rudnitsky V.A., Perchatkina O.E., Nikitina V.B., Vasilieva N.A., Agarkov A.A. Typology, constitutional-biological and clinicaldynamic characteristics of crisis conditions in borderline neuropsychiatric disorders. Siberian Herald of Psychiatry and Addiction Psychiatry. 2009; 5(56): 915 (in Russian).

10. Liu L., Liu C., Xudong Z. Linking Anger Trait with Somatization in Low-Grade College Students: Moderating Roles of Family Cohesion and Adaptability. Shanghai Archives of Psychiatry. 2017 February; 29(1): 3040. DOI: 10.11919/j.issn.1002-0829.216102

11. Farbod F., Farzaneh N., Bijan M.D., Mehdi G., Nosratollah N. Psychological Features in Patients with and without Irritable Bowel Syndrome: A Case-Control Study Using Symptom Checklist-90-Revised. Indian J
Psychiatry. $2015 \quad$ Jan-Mar;57(1):68-72. DOI: 10.4103/0019-5545.148526

12. Эриксон М., Росси Э. Человек из февраля. М.: Издво «Класс», 1995: 256. Erickson M., Rossi E. Man from February. Moscow: Klass Publishing House, 1995: 256 (in Russian).

13. Александер Ф. Психосоматическая медицина. Принципы и применение. Пер. с англ. А.М. Боковикова, В.В. Старовойтова; под науч. ред. С.Л. Шишкина. М.: Институт Общегуманитарных Исследований, 2006. Alexander F. Psychosomatic Medicine. Principles and Application. Translation from English A.M. Bokovikov, V.V. Starovoitov. Scientific editors S.L. Shishkin. Moscow: Institute for Humanitarian Research, 2006 (in Russian).

14. Opler D. A Practical Approach to Interviewing a Somatizing Patient. Current Psychiatry. 2017 July; 16(7):46-47.

15. Смулевич А.Б., Волель Б.А., Медведев В.Э., Терентьева М.А., Фролова В.И., Самушия М.А., Выборных Д.Э., Шафигуллин М.Р. Развития личности при соматических заболеваниях (к проблеме нажитой ипохондрии). Психические расстройства в общей медицине. 2008; 2(4-11). Smulevich A.B., Volel B.A., Medvedev V.E., Terentyeva M.A., Frolova V.I., Samushiya M.A., Vybornnykh D.E., Shafigullin M.R. [Razvitiya lichnosti pri somaticheskikh zabolevaniyakh (k probleme nazhitoy ipokhondrii)]. Personal development in somatic diseases (to the problem of acquired hypochondria). Psikhicheskiye rasstroystva $v$ obshchey meditsine - Mental Disorders in General Medicine. 2008; 2 (4-11) (in Russian).

16. Психосоматические расстройства: Руководство для практических врачей / Под ред. А.Б.Смулевича. М. : МЕДпресс-информ, 2019: 496. [Psikhosomaticheskiye rasstroystva] - Psychosomatic Disorders: A Guide for Practitioners / Edited by A.B. Smulevich. Moscow: MEDpress-Inform Publishing House, 2019: 496 (in Russian).

17. Agarwal V., Srivastava Ch., Sitholey P. Clinical Practice Guidelines for the Management of Somatoform Disorders in Children and Adolescents Indian Journal of Psychiatry. 2019 Jan; 61(8): 241-246. DOI:10.4103/psychiatry.IndianJPsychiatry_494_18

18. Menon V., Rajan T., Kuppili P., Sarkar S. Cognitive Behavior Therapy for Medically Unexplained Symptoms: A Systematic Review and Meta-Analysis of Published Controlled Trials. Indian Journal of Psychological Medicine. 2017 July; 39 (4): 399. DOI: 10.4103/IJPSYM.IJPSYM_17_17

Поступила в редакцию 04.02.2020 Утверждена к печати 01.06.2020

Костин Алексей Константинович, к.м.н., научный сотрудник отделения пограничных состояний. Researcher ID J-2397-2017. ORCID ID 0000-0002-6006-4853. Author ID РИНЦ 625519. SРIN-код РИНЦ 3564-8249.

Рудницкий Владислав Александрович, д.м.н., ведущий научный сотрудник отделения пограничных состояний. профессор кафедры социальной работы, социальной и клинической психологии ФГБОУ ВО СибГМУ Минздрава России. Researcher ID S-5745-2016. ORCID ID 0000-0003-1089-8793. Author ID РИНЦ 125291. SРIN-код РИНЦ 7358-7174. rudnizki9@ mail.ru

Сазонова Ольга Владимировна, врач-психиатр первого клинического психиатрического отделения. 
Никитина Валентина Борисовна, д.м.н., заведующая лабораторией клинической психонейроиммунологии и нейробиологии. Researcher ID B-9926-2012. Author ID Scopus 55640240200. ORCID ID 0000-0002-1644-770X. Author ID РИНЦ 154172. SРІN-код РИНЦ 3687-7727. valentina08@ sibmail.com

Епанчинцева Елена Макаровна, к.м.н., заведующая первым клиническим психиатрическим отделением.

Иванова Алла Алимомедовна, к.п.н., медицинский психолог консультативно-диагностического отделения.

Гарганеева Наталья Петровна, д.м.н., профессор, профессор кафедры общей врачебной практики и поликлинической терапии ФГБОУ ВО СибГМУ Минздрава России.

Цыбульская Елена Владимировна, медицинский психолог первого клинического психиатрического отделения.

Перчаткина Ольга Эрнстовна, к.м.н., заведующая отделом координации научных исследований. Researcher ID I-8664-2017. Author ID Scopus 57202383115. ORCID ID 0000-0001-5538-1304. Author ID РИНЦ 629511. SPINкод РИНЦ 6299-0859. роа@antline.ru

Белокрылова Маргарита Федоровна, д.м.н., ведущий научный сотрудник отделения пограничных состояний, профессор кафедры психиатрии, наркологии и психотерапии ФГБОУ ВО СибГМУ Минздрава России. Researcher ID S-4150-2016. Author ID Scopus 6506164731. ORCID ID 0 0000-0003-2497-6684. Аuthor ID РИНЦ 272592. SPIN-код РИНЦ 8197-0723. belmf@yandex.ru

Костин Алексей Константинович, арех79@sibmail.com

\title{
UDC 616.891.6-056.3:615.214:616.8-085.851:615.862-044.4
}

For citation: Kostin A.K., Rudnitsky V.A., Sazonova O.V., Nikitina V.B., Epanchintseva E.M., Ivanova A.A., Garganeeva N.P., Tsybulskaya E.V., Perchatkina O.E., Belokrylova M.F. Clinical and socio-psychological factors determining adherence to treatment of patients with somatoform disorders. Siberian Herald of Psychiatry and Addiction Psychiatry. 2020; 2 (107): 14-25. https://doi.org/10.26617/1810-3111-2020-2(107)-14-25

\section{Clinical and socio-psychological factors determining adherence to treatment of patients with somatoform disorders}

\section{Kostin A.K., 1, 2Rudnitsky V.A., 1Sazonova O.V., 1Nikitina V.B., 1Epanchintseva E.M., 1 Ivanova A.A., 2Garganeeva N.P., 1Tsybulskaya E.V., 1Perchatkina O.E., 1, 2 Belokrylova M.F.}

\author{
${ }^{1}$ Mental Health Research Institute, Tomsk National Research Medical Center, Russian Academy of Sciences \\ Aleutskaya Street 4, 634014, Tomsk, Russian Federation \\ ${ }^{2}$ Siberian State Medical University \\ Moskovsky Trakt 2, 634050, Tomsk, Russian Federation
}

\begin{abstract}
Currently, somatoform disorders, and especially manifold somatoform symptoms, widespread among employable population, often for a long time remain without proper and adequate diagnosis and treatment, and therefore have a tendency to a chronic course. Despite a significant number of publications, researchers pay insufficient attention to clinical manifestations, social and microsocial factors in the pathogenesis of somatoform disorders. Objective: to study the relationship of clinical and socio-psychological factors that determine compliance and prognosis in the treatment of somatoform disorders. Materials and Methods: 150 patients (53 men and 97 women) were examined based on the Borderline States Department of the Mental Health Research Institute, mean age was $40.4 \pm 4.5$ years with diagnosed somatoform disorder in accordance with the ICD-10 diagnostic criteria. Patients were subdivided according to age parameter, clinical picture of the course of the disease, and clinical and pathogenetic variant. We used clinical, psychopathological, clinical-dynamic, clinical-follow-up, psychological (Spielberger-Khanin scale, MPIT multi-profile personality investigation technique, Actual mental state test, Toronto alexithymia scale and E. Hein test (1988) to determine copying-mechanisms modified by I.Ya. Stoyanova), statistical methods. Results: analysis of psycho-traumatic situations revealed that intra-family psycho-injuries (63.3\%) were of the greatest significance. Abnormal forms of upbringing occurred in $92.7 \%$ of patients. The peculiarities of inner ideas of the disease in patients
\end{abstract}


with somatoform disorders, depending on the predominance of cognitive, behavioral, and affective response patterns, determined the formation and state of the therapeutic alliance and adherence to therapy. The main clinical and pathogenetic variants, social and micro-social factors affecting the process of psychopharmacotherapy and complex psychosocial rehabilitation of patients were considered. Conclusion: psychological, individual and personality traits of patients, the styles of their family upbringing and functioning make a significant contribution to the development of mental maladjustment, have a significant impact on the formation and course of somatoform disorders, prevent the formation of full compliance at all stages of therapy and rehabilitation of patients, determine the prognosis and indications for long-term psychotherapeutic support of patients after discharge from a psychiatric hospital.

Keywords: nonpsychotic mental disorders, somatoform disorders, maladaptation, peculiarities of inner ideas of disease, clinical and socio-psychological factors, accuracy of therapeutic appointments, personalized therapy, psychotherapy, psychocorrection, psychopharmacotherapy.

\section{Received February 04.2020}

Accepted June 01.2020

Kostin Alexey K., PhD, researcher, Borderline States Department, Mental Health Research Institute, Tomsk National Research Medical Center, Russian Academy of Sciences, Tomsk, Russian Federation. Researcher ID J-2397-2017. ORCID ID 0000-0002-6006-4853. Author ID РИНЦ 625519. SPIN-код РИНЦ 3564-8249.

Rudnitsky Vladislav A., MD, lead researcher, Borderline States Department, Mental Health Research Institute, Tomsk National Research Medical Center, Russian Academy of Sciences, Tomsk, Russian Federation; professor, Department of Social Work, Social and Clinical Psychology, Siberian State Medical University, Ministry of Health of Russia, Tomsk, Russian Federation. Researcher ID S-5745-2016. ORCID ID 0000-0003-1089-8793. Author ID РИНЦ 125291. SPIN-код РИНЦ 7358-7174. rudnizki9@mail.ru

Sazonova Olga V., psychiatrist of the First Clinical Unit, Mental Health Research Institute, Tomsk National Research Medical Center, Russian Academy of Sciences, Tomsk, Russian Federation.

Nikitina Valentina B., MD, Head of the Laboratory of Clinical Psychoneuroimmunology and Neurobiology, Mental Health Research Institute, Tomsk National Research Medical Center, Russian Academy of Sciences, Tomsk, Russian Federation. Author ID Scopus 55640240200. ORCID ID 0000-0002-1644-770Х. Author ID РИНЦ 154172. SPIN-код РИНЦ 3687-7727. valentina08@ sibmail.com

Epanchintseva Elena M., PhD, Head of the First Clinical Unit, Mental Health Research Institute, Tomsk National Research Medical Center, Russian Academy of Sciences, Tomsk, Russian Federation.

Ivanova Alla A., PhD for Psychology, medical psychologist of Consultative-Diagnostic Unit, Mental Health Research Institute, Tomsk National Research Medical Center, Russian Academy of Sciences, Tomsk, Russian Federation.

Garganeeva Natalya P., MD, Professor, professor, Department of General Medical Practice and Outpatient Therapy, Siberian State Medical University, Ministry of Health of Russia, Tomsk, Russian Federation.

Tsybulskaya Elena V., medical psychologist of the First Clinical Unit, Mental Health Research Institute, Tomsk National Research Medical Center, Russian Academy of Sciences, Tomsk, Russian Federation.

Perchatkina Olga E., PhD, Head of the Department of Coordination of Research, Mental Health Research Institute, Tomsk National Research Medical Center, Russian Academy of Sciences, Tomsk, Russian Federation. Researcher ID I-8664-2017. Author ID Scopus 57202383115. ORCID ID 0000-0001-5538-1304. Author ID РИНЦ 629511. SPIN-код РИНЦ 6299-0859. poa@antline.ru

Belokrylova Margarita F., MD, lead researcher, Borderline States Department, Mental Health Research Institute, Tomsk National Research Medical Center, Russian Academy of Sciences, Tomsk, Russian Federation; professor of the Department of Psychiatry, Addiction Psychiatry and Psychotherapy, Siberian State Medical University, Tomsk, Russian Federation. Researcher ID S-4150-2016. Author ID Scopus 6506164731. ORCID ID 0 0000-0003-24976684. Author ID РИНЦ 272592. SРIN-код РИНЦ 8197-0723. belmf@yandex.ru

Bokhan Nikolay A., academician of RAS, MD, Professor, Honored Scientist of the Russian Federation, Head of Addictive States Department, director of Mental Health Research Institute, Tomsk National Research Medical Center, Russian Academy of Sciences; Head of the Department of Psychiatry, Addiction Psychiatry and Psychotherapy, Siberian State Medical University, Tomsk, Russian Federation. Author ID Scopus 6506895310. ORCID ID 0000-00021052-855X. Researcher ID P-1720-2014. Author ID RSCI 152392. SPIN-код RSCI 2419-1263.

Kostin Alexey K., apex79@sibmail.com 